\title{
Rapid escalation of coastal flood exposure in US municipalities from sea level rise
}

\author{
Scott Kulp $^{1} \cdot$ Benjamin H. Strauss ${ }^{1}$
}

Received: 18 July 2016 / Accepted: 31 March 2017 / Published online: 10 May 2017

(C) The Author(s) 2017. This article is an open access publication

\begin{abstract}
Rising sea levels are increasing the exposure of populations and infrastructure to coastal flooding. While earlier studies estimate magnitudes of future exposure or project rates of sea level rise, here, we estimate growth rates of exposure, likely to be a key factor in how effectively coastal communities can adapt. These rates may not correlate well with sea level rise rates due to varying patterns of topography and development. We integrate exposure assessments based on LiDAR elevation data with extreme flood event distributions and sea level rise projections to compute the expected annual exposure of population, housing, roads, and property value in 327 medium-tolarge coastal municipalities circumscribing the contiguous USA, and identify those localities that could experience rapid exposure growth sometime this century. We define a rate threshold of $0.25 \%$ additive increase in expected annual exposure per year, based on its rarity of present-day exceedance. With unchecked carbon emissions under Representative Concentration Pathway (RCP) 8.5, the number of cities exceeding the threshold reaches 33 (18-59, 90\% CI) by 2050 and 90 (22-196) by 2100 , including the cities of Boston and Miami. Sharp cuts under RCP 2.6 limit the end-ofcentury total to 28 (12-105), versus a baseline of 7 cities in 2000. The methods and results presented here offer a new way to illustrate the consequences of different emission scenarios or mitigation efforts, and locally assess the urgency of coastal adaptation measures.
\end{abstract}

\section{Introduction}

Under worst-case scenarios, climate-driven sea level rise could exceed $2 \mathrm{~m}$ by the end of this century (Field et al. 2014; DeConto \& Pollard 2016; Kopp et al. 2014; Sweet et al. 2017), putting US land currently home to millions of people at risk of permanent inundation (Strauss et al. 2012; Hauer et al. 2016). More immediately, rising sea levels are adding to the height of

Electronic supplementary material The online version of this article (doi:10.1007/s10584-017-1963-7) contains supplementary material, which is available to authorized users.

Scott Kulp

skulp@climatecentral.org 
combined tide and storm surge events, or storm tides, increasing the frequency of extreme coastal flood events nationwide (Frumhoff et al. 2007; Cayan et al. 2008; Tebaldi et al. 2012; Buchanan et al. 2016).

The rate of climate change is a key factor determining whether adaptation is economically practical, probable, or even possible in different places (Klein et al. 2014; Barnett et al. 2015). But while rates of sea level rise have attracted great interest (Church \& White 2011; Hay et al. 2015; Kopp et al. 2016), to our knowledge, rates of rising coastal flood exposure have not. These rates may depart from sea level rates because of local patterns of topography and development. Projecting the speed of exposure growth and when it may exceed key thresholds under different scenarios can help identify localities that can benefit most from climate change mitigation, or where coastal resilience measures are most urgent.

Past work has illustrated potential future flood exposure by augmenting floodplains for select storm tide return levels with different sea level rise increments (e.g., Cooper et al. 2008; San Francisco Bay Conservation and Development Commission 2011). Other studies estimate expected economic damages, typically by integrating a flood height damage function with projections of annual flood event probabilities this century. Such techniques have been applied from city through global scales (Kirshen et al. 2008; Neumann et al. 2014; Houser et al. 2015; Hinkel et al. 2014; Dinan 2016), but these studies have focused on totals, rather than changing rates, of exposure or risk.

In this paper, we use the term "flood exposure" to denote population or infrastructure occupying land whose elevation is less than or equal to a given water height and which neither natural barriers nor known defenses protect. More specifically, we define "expected annual exposure" to coastal flooding, which integrates the annual probability distribution of flood heights with the exposure under each height, given the sea level projected each year. Compared to more traditional methods for assessing exposure with respect to a single water surface (e.g., under the 100-year storm surge (Hallegatte et al. 2013)), this probabilityweighted approach incorporates the potential impact of sea level rise across a wide range of flood events, from routine nuisance flooding to cyclonic storms.

In our analysis, we forecast and compare twenty-first-century growth rates in expected annual exposure for 327 US municipalities and four variables: population, housing units, property value, and road miles. We develop profiles of exposure as a function of flood height for each city-variable combination, and integrate these with projected local flood height probabilities over time under different carbon emissions and sea level scenarios (Sect. 2). With the resulting curves, we assess the magnitude and rate of increases in annual expected exposure under different carbon emissions pathways, and identify cities exceeding different thresholds (Sect. 3). Finally, we discuss the limitations of this method, along with possible implications for adaptation strategies by policy makers and planners (Sect. 4).

We select cities as the focus of this analysis because of their importance as units of governance and climate resilience planning (Castán Broto \& Bulkeley 2013; Bulkeley \& Betsill 2013).

\section{Methods}

\subsection{Profiles of exposure by elevation}

We assess population and asset exposure to coastal flooding and sea level rise by extending the core methodology of Strauss et al. (2012) into three main steps: developing inundation 
surfaces at closely spaced vertical increments above the high tide line, computing exposure under each surface for each municipality and variable considered, and interpolating.

To assess topography as required for this analysis, we employ LiDAR-based digital elevation models compiled and distributed by NOAA (2015), supplemented with the USGS Northern Gulf of Mexico Topobathymetric DEM (USGS 2014) in Louisiana, and the USGS National Elevation Dataset (Gesch et al. 2002) in the small fraction of land not covered by the other sources. We then recompute elevations relative to local mean higher high water (MHHW) levels at nearest neighbors in NOAA's VDatum grid (version 2.3.5) (Parker et al. 2003), measured in the National Tidal Datum Epoch (1983-2001). Employing a bathtub model, we threshold each pixel in the resulting digital elevation models to produce inundation surfaces at 0.25-7 $\mathrm{m}$ above MHHW, at 0.25-m increments. These surfaces are then refined by using connected component analysis to remove all low-lying subthreshold areas that the analysis indicates to be isolated by topography or levees from the ocean. Data from the Mid-term Levee Inventory (FEMA/USACE, acquired September 2013) is used for levees and other flood control structures. In Louisiana, we supplement this with data from Louisiana's Coastal Protection and Restoration Authority (CPRA Flood Protection GIS Database as of June 2015), and in Massachusetts, we include data provided by Chris Watson at UMass Boston, April 2014, based on MassGIS's Digital Orthophoto Topographic Breaklines, April 2003. These, and all other data sources used in this analysis, are listed for convenience in Table S9.

Because these sources lack data on flood control structure height or condition, for simplicity and analytic tractability, we treat all structures as high and strong enough to protect against any flood that would meaningfully influence our results. We also assume that no new protective structures will be built, because of the extreme uncertainty around whether, where and when any individual structure would be added. Some research has modeled future levee building decisions in the USA, but without the spatiotemporal resolution or confidence that would be required here (Neumann et al. 2014).

To develop our analysis of exposure, we use census block boundary, population, and housing data from the 2010 US census (US Census Bureau 2012), and recent property value (PV) estimates from Neumann et al. (2011) and the Florida Department of Revenue, all adjusted to 2012 dollars. We assume that population, housing unit, and PV density are zero over wetland areas delineated by the National Wetland Inventory (US Fish and Wildlife Service 2010), and compensate by proportionately increasing densities in the balance of each affected block (population, housing) or blockgroup (PV) area.

Since we use densities averaged over the dryland portions of census blocks (population, housing) or blockgroups (PV), our results would be biased if structures tend to be concentrated at higher or lower elevations within these units. To ensure that the results of this analysis are not overly sensitive to our uniform dryland density assumption, we perform a similar assessment of road exposure using spatially explicit road centerline data from the US Census. We reason that road density should correlate with development, and thus, results for roads should appear similar to other results, assuming that there is no elevation bias of structures within blocks or blockgroups. In this context, for consistency with our approach for other variables, we do not include roads over wetland areas in the exposure assessment (we assume that they are elevated).

We compute total population, housing unit, road length, and PV exposed under each inundation surface, and apply cubic Hermite interpolation to estimate any intermediate exposure values between the $0.25-\mathrm{m}$ water height increments. 
While we assess exposure given development as it exists today, population is likely to grow in low-lying coastal areas over the coming decades (Hauer et al. 2016). However, projecting growth with the high spatiotemporal resolution needed for the present analysis would add large uncertainties and require major, untested assumptions concerning behavior and adaptation measures in the face of changing flood frequencies. To mitigate the concern that static populations are nonetheless unrealistic, we primarily consider percent (rather than absolute) exposure within each municipality. This approach also better reflects the significance of the threat relative to each place as a whole and how it is developed today and allows us to more easily compare across municipalities.

\subsection{Expected exposure by year}

For each variable and within each municipality, we estimate the expected annual exposure (EAE) each year on the basis of an extreme value analysis of the distribution of daily water levels. In this computation, we integrate local sea level projections, parameterized models of extreme flood event probabilities, and exposures as functions of elevation.

Recently, Tebaldi et al. (2012) fitted the parameters of a generalized Pareto distribution (GPD) to historical heights and frequencies of extreme coastal flood events at more than $50 \mathrm{US}$ water level stations based on 30 years of hourly records. Here, we update parameters to fit the complete hourly record available at an expanded set of stations through the end of 2013 (at least 30 years of hourly records each; see Table S7). We then match each municipality $i$ with a single station, and use the median parameters of the GPD to define $P_{i}^{\mathrm{GPD}}(X>h)$ as the annual probability of at least one flood exceeding height $h$ (or, in an equivalent interpretation, as the annual probability of the maximum flood height at this station exceeding $h$ ). This probability function is defined for $h \geq \mu$, the location parameter of the GPD distribution (the threshold above which the water height observations are fit to the model). Below the location parameter, we assume that the annual number of exceedances at height $h$ follows a Poisson distribution, and so, the probability of at least one flood event exceeding $h$ can be defined as $P_{i}^{\text {Poisson }}$ $(X>h)=1-e^{-\lambda}$, where $\lambda$ is the average number of annual exceedances according the record. Together, $P_{i}^{\mathrm{GPD}}$ and $P_{i}^{\text {Poisson }}$ define our piecewise probability function, $P_{i}(X>h)$. The corresponding probability density function, $f_{i}(h)$, is computed by taking the derivative of the cumulative density function, equivalent to $\left(1-P_{i}(X>h)\right)$. We estimate this derivative using finite difference methods by sampling $P_{i}(X>h)$ at intervals of 0.1 up to $5 \mathrm{~m}$, noting that $f_{i}(h)$ is negligibly close to zero at all water level stations for $h>5 \mathrm{~m}$.

Then, defining $g_{i}^{V}(h)$ as the exposure of variable $V$ in place $i$ at flood height $h$, and $\operatorname{SLR}_{i}$, ${ }_{s}(t)$ as the projected sea level rise by year $t$ under Representative Concentration Pathway (RCP) carbon emission scenario $s$, the EAE can be approximated by using numerical quadrature to compute

$$
\operatorname{EAE}_{i, s}^{V}(t)=\int_{-\infty}^{\infty} f_{i}(h) \cdot g_{i}^{V}\left(h+\operatorname{SLR}_{i, s}(t)\right) d h \approx \int_{0 \mathrm{~m}}^{5 \mathrm{~m}} f_{i}(h) \cdot g_{i}^{V}\left(h+\operatorname{SLR}_{i, s}(t)\right) d h
$$

At each station, and under carbon emission scenarios RCP 2.6 (sharp cuts), 4.5, and 8.5 (high emissions), Kopp et al. (2014) produced 10,000 samples of simulated $\mathrm{SLR}_{i}$, $s(t)$ projections between 2000 and 2200, with 2000 as the baseline (zero) year, and incorporating local factors, such as land subsidence due to glacial isostatic adjustment, tectonics, and other non-climatic local effects computed from linear trends of historical tidal records, as well 
as global sea level forecasts. From these, we compute 10,000 samples of $\operatorname{EAE}_{i, s}^{V}(t)$ through 2100 , with which we may determine the 5th, 50th, and 95th percentiles of $\operatorname{EAE}_{i}^{V}$ at each year and scenario. We use these to report the $90 \%$ confidence intervals (CIs) for all quantities throughout this paper.

To reduce computation time, we consider only those coastal municipalities of larger absolute exposure impact, in which total population exceeds 10,000 and where exposure at $3 \mathrm{~m}$ above MHHW exceeds 10,000 people or $10 \%$ of the population, whichever is lower. The 3 -m threshold exceeds the computed $1 \%$ annual risk flood height for all water level stations in our analysis, except two outliers in Apalachicola, FL, and Washington, DC. Applying these constraints, all of the following analysis is performed on the remaining 327 coastal cities in the contiguous USA (Fig. 1).

\subsection{Expected annual exposure growth rates}

We have empirically found that using iterative least squares, $E A E_{i, s}^{V}(t)$ can be closely approximated $\left(r^{2}>0.99\right.$ in $96 \%$ of locations across all scenarios) by a logistic function,

$$
\Gamma_{i, s}^{V}(t)=t_{0}+\frac{t_{1-t_{0}}}{1+e^{-k(t-m)}}, t \in[2000,2100]
$$

finding constants $t_{0}, t_{1}, k$, and $m$ that minimize $\left|\Gamma_{i, s}^{V}(t)-\mathrm{EAE}_{i, s}^{V}(t)\right|$. The estimated EAE growth rate, $\frac{d \Gamma_{i, s}^{V}}{d t}(t)$, is then easily computed.

To identify locations that could experience problematically high exposure growth rates this century, we seek a rate threshold, $\varepsilon$, based on a qualitative assessment of the distribution of EAE growth in 2000 (Fig. 2). In the absence of past analysis linking particular EAE rates with

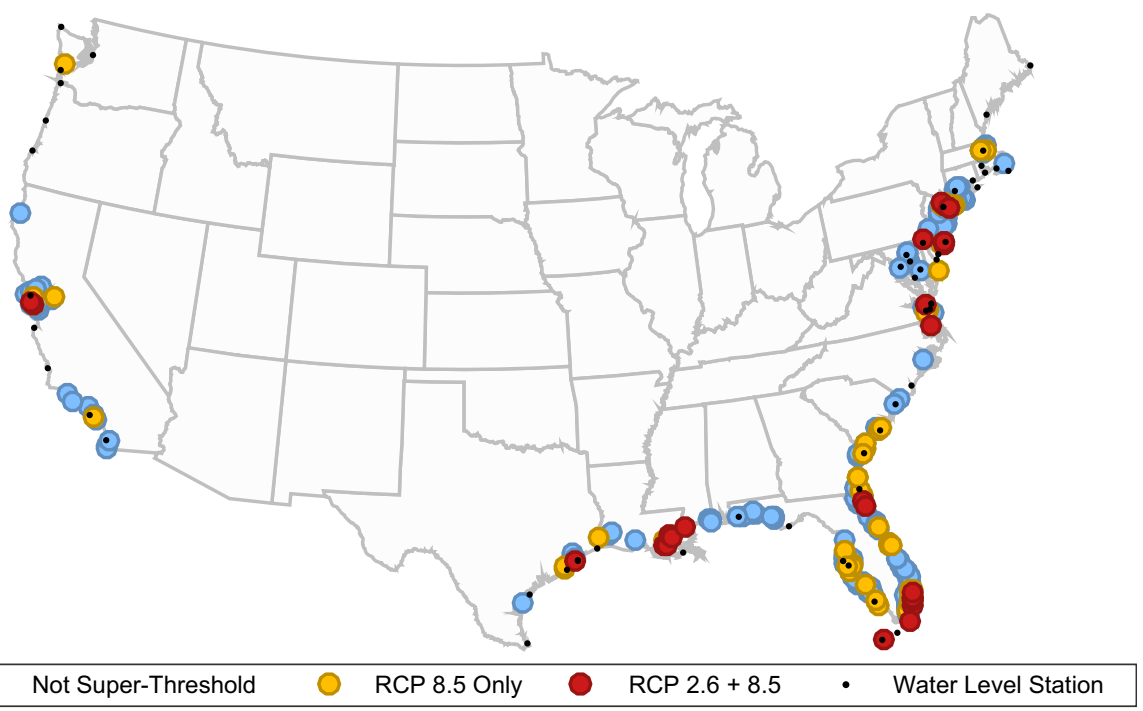

Fig. 1 Locations of all analyzed cities and water level stations. Dot colors indicate the lowest RCP scenario (if any) under which expected annual population flood exposure growth rate exceeds the threshold of $0.25 \%$ per year during the twenty-first century 

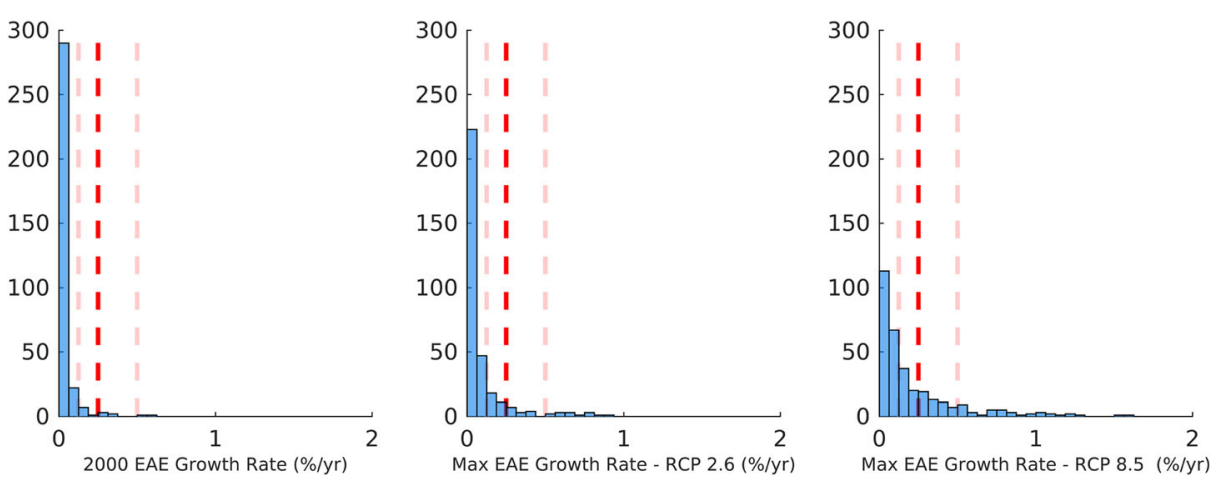

Fig. 2 Distributions of modeled expected annual population flood exposure growth rate (percent per year) across 327 municipalities in 2000 (left), as well as cities' projected maximum rate this century, under the RCP 2.6 (middle) and RCP 8.5 (right) emission scenarios. The rate threshold $\varepsilon=0.25 \%$ per year is indicated by the red lines, and the alternative rate thresholds $\varepsilon=0.125 \%$ per year and $\varepsilon=0.5 \%$ per year are indicated by the pink lines

the emergence of difficulties and to limit false positives, we primarily use a rate threshold at the high tail (98th percentile) of this distribution, at $\varepsilon=0.25 \%$ per year.

This threshold exceeds the estimated 2000 rate for a number of important municipalities, such as Miami Beach, which is already investing hundreds of millions of dollars into coastal flood mitigation strategies (Allen 2016). In a second example, among the few locations above this threshold in 2000, Atlantic City is already experiencing frequent and accelerating coastal flooding, and is struggling to respond (Hayden 2016). We posit that cities expected to reach this threshold mid-century must begin adaptation efforts and infrastructure improvements in advance to avoid similar challenges. We also provide results at lower $(\varepsilon=0.125 \%$ per year, 95th percentile) and even higher $(\varepsilon=0.5 \%$ per year, $>99$ th percentile) rate thresholds in Tables 1 and S5.

We classify those municipalities where $\frac{d \Gamma_{i, s}^{V}}{d t}(t)$ exceeds $\varepsilon$, with "super-threshold" status, and define the year in which this threshold is reached as its "rate threshold year," $t_{i}^{(r)}$. In some super-threshold cities, EAE growth rate drops again to subthreshold levels later in the century, such as when total exposure becomes saturated, but these locations are still included in total counts.

Table 1 Number of municipalities whose projected population EAE growth rate exceeds the given thresholds (with $90 \%$ CIs) by 2000, 2050, and 2100 under emission scenarios RCP 2.6, 4.5, and 8.5

\begin{tabular}{llclc}
\hline Scenario & Threshold (\%/year) & 2000 & 2050 & 2100 \\
\hline RCP 2.6 & 0.125 & $16(8-36)$ & $43(21-78)$ & $57(21-165)$ \\
& 0.25 & $7(3-16)$ & $22(10-45)$ & $28(12-105)$ \\
RCP 4.5 & 0.5 & $2(0-5)$ & $10(3-19)$ & $14(3-52)$ \\
& 0.125 & $15(8-27)$ & $47(25-91)$ & $88(26-195)$ \\
& 0.25 & $7(5-9)$ & $26(10-48)$ & $44(14-124)$ \\
RCP 8.5 & 0.5 & $1(0-2)$ & $10(3-23)$ & $17(3-70)$ \\
& 0.125 & $15(5-31)$ & $66(36-112)$ & $147(45-272)$ \\
& 0.25 & $7(0-13)$ & $33(18-59)$ & $90(22-196)$ \\
& 0.5 & $2(0-5)$ & $15(6-30)$ & $40(10-134)$ \\
\hline
\end{tabular}

All rates are computed from logistic functions fitted to modeled EAE projections, so counts of super-threshold locations in 2000 can vary slightly across emission scenarios 


\subsection{Station choice and sensitivity analysis}

We choose the closest water level station to each municipality by straight-line distance, except in Florida, where we do not allow pairing of stations and municipalities across the peninsula. At places on the Atlantic coast of Florida, we consider only the stations at Vaca Key or Fernandina Beach, while on the Gulf Coast, Fernandina Beach station is not used with any municipality.

Some places, such as Miami, are located far $(>100 \mathrm{~km})$ from their closest stations. As both sea level rise projections and extreme water level distributions can vary among stations, we assess the sensitivity of computed EAE to both station choice and distance by repeating all analyses at each municipality using a second nearby water level station, chosen to ensure that the municipality falls spatially between the first and second stations along the coastline. Treating the EAE at the primary station as truth, we compare the computed maximum EAE growth and rate threshold years at each place, evaluating the impact of interstation distances on this error.

\section{Results}

\subsection{Expected annual exposure and rate threshold year analysis}

We find that in 2000, 7 (0-13) municipalities of over 10,000 people had already begun to experience population EAE growth rates exceeding the $\varepsilon=0.25 \% /$ year threshold, including Atlantic City, NJ, and Poquoson, VA (Fig. 3), based on RCP 8.5 (closest to observed emissions). Continuation of RCP 8.5 could increase the total to 33 (18-59) super-threshold municipalities by 2050 and 90 (22-196) by the end of the century. Aggressive cuts to emissions (RCP 2.6) would reduce estimates to $22(10-45)$ super-threshold municipalities by 2050 and $28(12-105)$ by 2100 . Table 1 presents additional super-threshold city totals under a variety of emission scenarios and threshold levels. The largest cities projected to exceed threshold rates of EAE growth this century under RCP 8.5 include Boston, MA (total population of 617,594), Miami, FL $(399,457)$, and Stockton, CA $(277,588)$. Under RCP 2.6, the largest super-threshold cities include San Mateo, CA $(97,207)$, Miami Beach, FL $(87,779)$, and Redwood City, CA (76,815).

Super-threshold municipality count appears insensitive to the choice of exposure metric. Annual expected (percent) exposure of housing units produces very similar results to the previous population EAE, with 92 (21-210) places reaching super-threshold status by 2100 under RCP 8.5 using this measure, and 28 (11-111) under RCP 2.6. EAE of PV tends to be slightly higher, with 104 (25-22) super-threshold places under RCP 8.5 and 31 (7-120) under RCP 2.6. However, as PV density is computed at the blockgroup level (on average $39 \times$ larger in area than blocks for the coastal USA as a whole), exposure analysis of PV may be less accurate than that of population/housing units. Exposed road miles are computed using precise centerlines of road segments and thus may be more accurate than density-based categories; see 94 (28-211) super-threshold municipalities under RCP 8.5 and 36 (12-109) under RCP 2.6. Due to the similar results that we find under each category, we focus on population exposure for the remainder of this analysis, as an indicator of where human interests are greatest.

Under RCP 8.5, Atlantic City, NJ, with a total population of 39,558 in 2010, experiences the largest total growth of population EAE out of all municipalities, from $9.9 \%$ in 2000 , to 

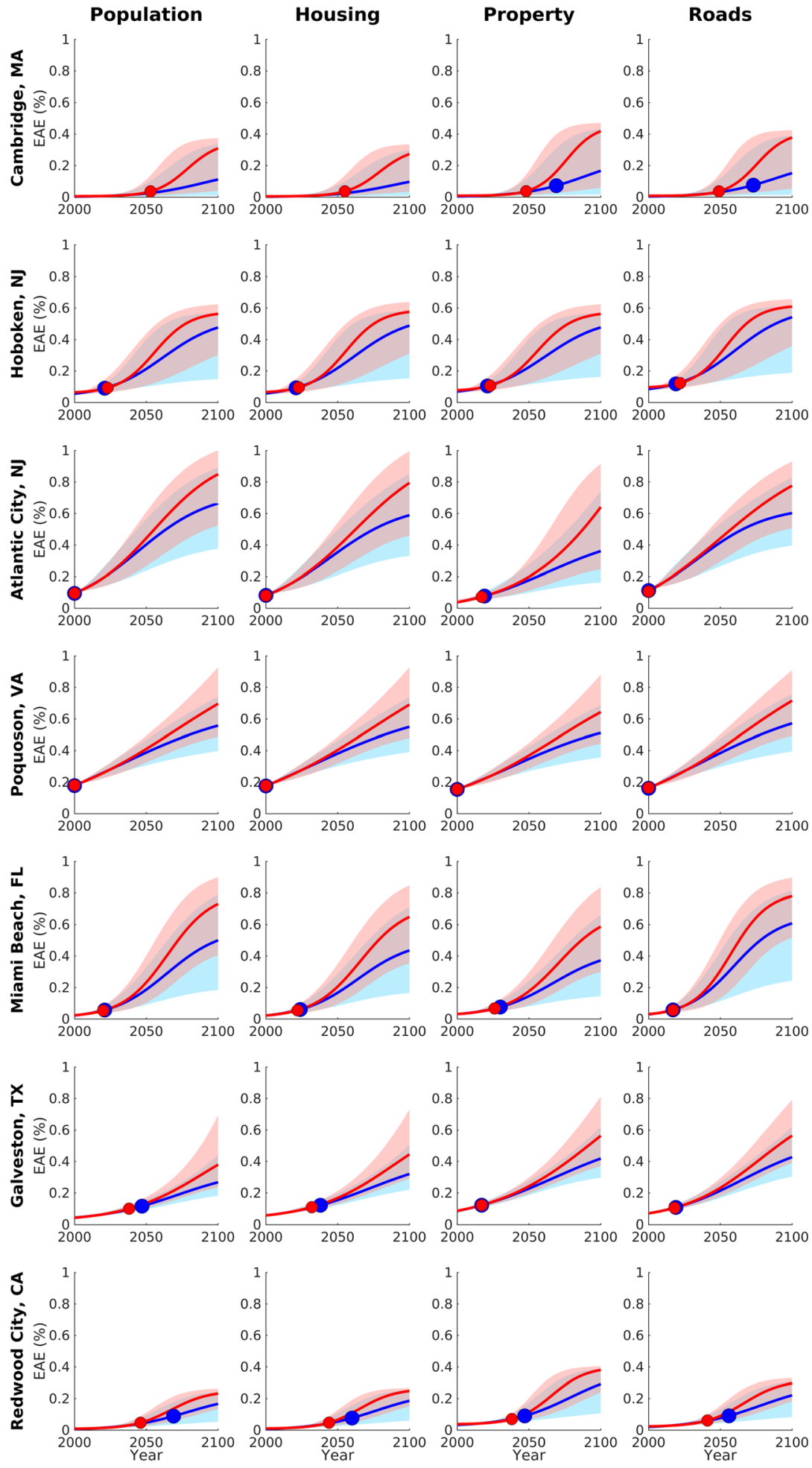
Fig. 3 Evolution of expected annual percent exposure this century at seven characteristic municipalities using four different exposure variables, with $90 \%$ CIs, under the RCP 8.5 (red) and RCP 2.6 (blue) emission scenarios. Dots indicate years when cities cross the $0.25 \%$ per year rate threshold under the median projection for each emission scenario

$85.2 \%$ (53.2-98.6\%) in 2100. Miami Beach, FL, with total 2010 population of 87,779, follows a similar rise, from 2.5 to $74.5 \%$ (40.2-90.9\%). Houma, LA, and Key Biscayne, FL, reach the highest maximum rates of EAE growth during the twenty-first century, at 1.58 and $1.51 \%$ per year, respectively. Magnitudes and rates of EAE growth are strongly reduced under RCP 2.6 (Tables S1-S4).

The city with the largest increase in absolute (rather than percent) expected annual population exposure is New York City, rising from 23,700 in 2000, to 206,700 (73,000430,500 ) in 2100 under RCP 8.5. However, the city never achieves super-threshold status, as percent EAE and its growth rate are consistently low due to the city's large total population. Among cities which exceed population EAE growth rate thresholds, Miami Beach, FL, has the highest absolute EAE jump, from 2200 in 2000 to 65,400 (35,300-79,800) in 2100.

Under RCP 8.5, Florida contains $42 \%$ of all super-threshold cities (roughly three quarters of which are on the Atlantic side), while New Jersey has another $10 \%$. Further, $69 \%$ of all superthreshold cities are on the Atlantic coast, $23 \%$ are on the Gulf coast, and $8 \%$ are on the Pacific coast. Under RCP 2.6, while impacts diminish, these proportions remain largely consistent.

Sorting by maximal second derivative $\frac{d^{2} \Gamma_{i, s}^{V}}{d y^{2}}(y)$, we evaluate municipalities at greatest risk of sudden acceleration in EAE. Among places with a peak before 2100, Key Biscayne, FL, has the largest maximum second derivative under RCP 8.5 at $6.6 \mathrm{e}-4 \% / \mathrm{year}^{2}$, and median EAE growth at this location tops out at $1.52 \%$ year. Other places of high population $(>50,000)$ and second derivative (median $>3.0 \mathrm{e}-4 \% /$ year $^{2}$ ) under unchecked carbon emissions include Hoboken, NJ, Homestead, FL, and Miami Beach, FL. However, we note that the late-century EAE of locations with high second derivatives tends to be exceptionally sensitive (with wide CIs) to the sea level rise function, such as in Key Biscayne, at 51.8\% (7.4-80.4\%) in 2100 under RCP 8.5.

Supplementary Tables S1-S8 present more extensive details of this analysis, including the EAE (and derivatives thereof) (S1-S4), rate threshold years using the $\varepsilon=0.25 \%$ threshold, in addition to a lower $(\varepsilon=0.125 \%)$ and higher $(\varepsilon=0.5 \%)$ threshold (S5), and the fitted logistic parameters (S6). Table S7 provides the GPD PDF parameters at each water level station, and Table S8 lists the closest station to each city.

\subsection{Station choice and sensitivity analysis}

Comparing (median) rate threshold years given projections at each municipality's primary and secondary water level stations (Fig. 4), we find that under RCP 8.5, 72\% that are classified as super-threshold at either station will be classified as such at both. Where the interstation distance is less than $300 \mathrm{~km}$, this number rises to $82 \%$. This is consistent with RCP 2.6, where $83 \%$ of cities that are super-threshold at either will be super-threshold at both, rising to $90 \%$ below the 300-km interstation distance threshold.

Across municipalities which are super-threshold at both stations under RCP 8.5, the rate threshold year RMSE is 14.8 years, dropping below the $300-\mathrm{km}$ distance threshold to 8.6 years, less than a decade. The maximum EAE growth rate RMSE is 0.05 or $0.02 \% / y$ ear correspondingly. Under RCP 2.6, the rate threshold year RMSE is 25.5 years, or 8.2 years below $300 \mathrm{~km}$, and the maximum EAE rate RMSE is 0.02 or $0.01 \%$ correspondingly. 

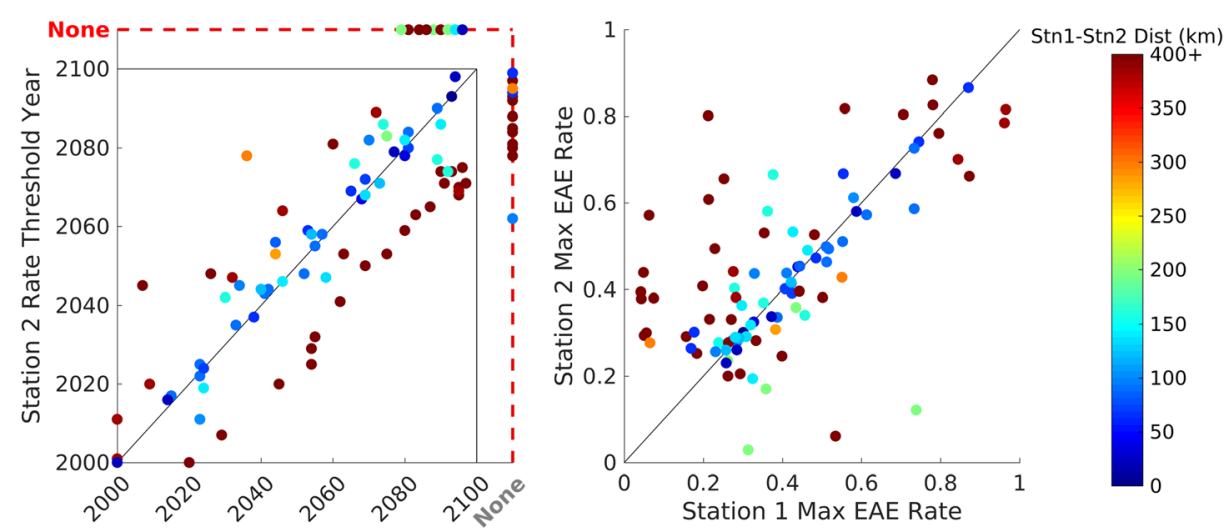

Station 1 Rate Threshold Year

Fig. 4 Sensitivity of median rate threshold year (left) and maximum EAE growth rate (right) to station choice and station distance. Each marker represents a municipality that experiences rising expected annual exposure exceeding the rate threshold by 2100 given sea level rise projections under RCP 8.5 and extreme water level distributions at its nearest water level station ("Station 1," $x$-axis) or given the same parameters at its secondnearest water level station ("Station 2," $y$-axis), or both. Markers are colored by the distance between station 1 and station 2

\section{Discussion}

From the station distance sensitivity analysis, we find that both the fact and timing of a city's exceedance of EAE growth rate thresholds, as well as the maximum magnitude of EAE growth, appear consistent across matched stations up to $300 \mathrm{~km}$ apart. Of the 327 municipalities, all but four are closer than $300 \mathrm{~km}$ to the closest water level station, and those four outliers all have low exposure risk, with EAE less than $5 \%$ by 2100 under RCP 8.5. Since all cities projected to exceed the rate threshold lie within $300 \mathrm{~km}$ of the nearest water level station, the sensitivity analysis results imply that our analyses are locally applicable for each city.

In a second set of factors contributing noise to this analysis, ocean circulation and mean sea level experience seasonal, annual, and decadal fluctuations around long-term trends of local sea surface height (Ferry et al. 2000; Volkov 2003; Jackson et al. 2016). The analysis in this report thus reflects average expectations of annual exposure, and should not be interpreted as indicating precise timing or exposure levels.

Several factors may cause actual exposure growth rates to diverge from our projections. Instability of the Antarctic ice sheets may cause sea levels to rise much faster in the second half of the century (DeConto \& Pollard 2016) than under the projections used here, pointing to greater threats than we find. We do not account for waves. Furthermore, while we assume that the distribution of extreme flood heights above sea level at any given time will not change, some studies suggest that the frequency of tropical cyclones may change, and their intensities could rise (Knutson et al. 2010; Knutson et al. 2013; Emanuel 2013). Analysis by Houser et al. (2015) suggests that the overall impact of such changes in activity would likely increase expected annual coastal flood damages. Counterbalancing these factors in some measure, the elevation threshold approach employed here is nearly certain to overestimate flooding exposure, as it does not account for the time required for flood waters to reach their full extent during any given event due to distance and friction (Gallien et al. 2014). In many cases, waters 
should begin to recede before reaching the full spatial extent implied by a threshold analysis employing the temporary peak flood level.

While we exclude low-lying areas protected by levees and other features as described in Sect. 2, we do not consider any other mitigation strategies currently in place, such as flood pumps, or levees not in our database. We do not consider levee height in our analysis due to lack of such data nationwide but rather assume that all levees are strong and tall enough to protect against any flood. The analysis does not capture potential protection from fine features such as small seawalls (principally used to protect against erosion), which appear neither in elevation nor levee data. Furthermore, as this is an assessment of potential risk given current infrastructure, and is meant to identify municipalities likely to face major protective needs, this analysis also assumes no further adaptation this century. However, EAE growth rates in some cities could be greatly reduced if infrastructure is improved.

Some municipalities with high EAE growth rates, such as Hoboken, NJ, and Boston, MA, possess low-lying land currently protected by levees or other major flood control structures. In these cases, sharp EAE growth may occur when floods high enough to find a path around protective features become sufficiently frequent. High second derivatives, $\frac{d^{2} \Gamma_{i, s}^{V}}{d y^{2}}(y)$, appear particularly suggestive of this condition. Flood mitigation strategies such as raising or extending existing structures might be feasible in these cases, and the year of maximum second derivative could be seen as suggesting a timeframe for the urgency of preparatory efforts. Municipalities on barrier islands, with their typically long, narrow, flat, and low-lying geometry, are another class of places showing high EAE growth rates, where successful defensive strategies are more difficult to imagine in the long run. The rare cities in this analysis which lie far inland, at the extreme of tidal influence, e.g., near the tip of a long arm of a bay, such as Stockton, CA, may conversely have greater than average opportunities to defend.

\section{Summary and conclusions}

Climate-driven sea level rise will continue to worsen coastal flood exposure in the decades ahead at different rates across different cities and periods. The methods presented here can be used to assess the evolution of EAE this century at coastal municipalities, and identify those locations at greatest risk of exceptional growth rates. Unchecked global carbon emissions could trigger high exposure growth rates in nearly 100 US cities this century, exceeding almost all contemporary rates, while immediate, deep cuts to emissions could reduce this number by nearly two thirds, highlighting a major potential benefit of climate change mitigation. However, even under the low emissions pathway, more than 20 cities could still face high rates and require effective adaptation strategies to avoid frequent flood damage in the coming decades.

Acknowledgments The authors gratefully acknowledge Claudia Tebaldi for statistical advice, Bob Kopp for sea level rise projections, and both together with Michael Oppenheimer for thoughtful comments on the manuscript. The research leading to these results has received funding from the Bermuda Institute of Ocean Sciences and the Kresge Foundation.

Open Access This article is distributed under the terms of the Creative Commons Attribution 4.0 International License (http://creativecommons.org/licenses/by/4.0/), which permits unrestricted use, distribution, and reproduction in any medium, provided you give appropriate credit to the original author(s) and the source, provide a link to the Creative Commons license, and indicate if changes were made. 


\section{References}

Allen G (2016) As waters rise, Miami beach builds higher streets and political willpower. NPR

Barnett $\mathrm{J}$ et al. (2015) From barriers to limits to climate change adaptation: path dependency and the speed of change. Ecology and Society, 20(3)

Buchanan MK et al (2016) Allowances for evolving coastal flood risk under uncertain local sea-level rise. Clim Chang 137(347):347-362

Bulkeley H, Betsill MM (2013) Revisiting the urban politics of climate change. Environmental Politics 22(1): 136-154

Castán Broto V, Bulkeley H (2013) A survey of urban climate change experiments in 100 cities. Glob Environ Chang 23(1):92-102

Cayan DR et al (2008) Climate change projections of sea level extremes along the California coast. Clim Chang 87(S1):57-73

Church JA, White NJ (2011) Sea-level rise from the late 19th to the early 21st century. Surv Geophys 32(4-5): 585-602

Cooper M, Beevers M, Oppenheimer M (2008) The potential impacts of sea level rise on the coastal region of New Jersey. USA, Climatic Change

DeConto RM, Pollard D (2016) Contribution of Antarctica to past and future sea-level rise. Nature 531(7596): $591-597$

Dinan T (2016) CBO's approach to estimating expected hurricane damage. Congressional Budget Office, Washington, D.C.

Emanuel KA (2013) Downscaling CMIP5 climate models shows increased tropical cyclone activity over the $21 \mathrm{st}$ century. Proc Natl Acad Sci U S A 110(30):12219-12224

Ferry N, Reverdin G, Oschlies A (2000) Seasonal sea surface height variability in the North Atlantic Ocean. Journal of Geophysical Research: Oceans 105(C3):6307-6326

Field C, Barros VR, Dokken DJ, Mach KJ, Mastrandrea MD, Bilir TE, Chatterjee M, Ebi KL, Estrada YO, Genova RC, Girma B, Kissel ES, Levy AN, MacCracken S, Mastrandrea PR, White LL (2014) Climate change 2014: impacts, adaptation, and vulnerability. Contribution of working group II to the fifth assessment report of the intergovernmental panel on climate change. Cambridge University Press, Cambridge and New York

Florida Department of Revenue, "Florida Property Valuation and Tax Data." Available Online: http://floridarevenue.com/dor/property/resources/data.html. Accessed 24 Apr 2017

Frumhoff PC et al. (2007) Confronting climate change in the U.S. northeast: science, impacts, and solutions., Cambridge, MA: Union of Concerned Scientists

Gallien TW, Sanders BF, Flick RE (2014) Urban coastal flood prediction: integrating wave overtopping, flood defenses and drainage. Coast Eng 91:18-28

Gesch D et al (2002) The National Elevation Dataset. Photogramm Eng Remote Sens 68(1):5-32

Hallegatte $\mathrm{S}$ et al (2013) Future flood losses in major coastal cities. Nat Clim Chang 3(9):802-806

Hauer ME, Evans JM, Mishra DR (2016) Millions projected to be at risk from sea-level rise in the continental United States. Nat Clim Chang 6(7):691-695

Hay CC et al (2015) Probabilistic reanalysis of twentieth-century sea-level rise. Nature 517:481-484

Hayden ME (2016) Atlantic City gambles on rising seas. National Geographic

Hinkel J et al (2014) Coastal flood damage and adaptation costs under 21st century sea-level rise. Proc Natl Acad Sci U S A 111(9):3292-3297

Houser T et al. (2015) Economic risks of climate change: an American prospectus, Columbia University Press

Jackson LC et al (2016) Recent slowing of Atlantic overturning circulation as a recovery from earlier strengthening. Nat Geosci 9(7):518-522

Kirshen P, Knee K \& Ruth M (2008) Climate change and coastal flooding in Metro Boston: impacts and adaptation strategies. Climatic Change

Klein RJT, Midgley GF, Preston BL, Alam M, Berkhout FGH, Dow K, Shaw R, Botzen W, Buhaug H, Butzer K, Keskitalo ECH, Li Y, Mateescu E, Muir-Wood R, Mustelin J, Reid H, Rickards L, Scorgie S, Smith TF, Thomas A, Watkiss P, Wolf J (2014) Adaptation opportunities, constraints, and limits. In: Gitay H, Thurlow J (eds) Climate change 2014: impacts, adaptation, and vulnerability. Part a: global and sectoral aspects. Contribution of Working Group II to the Fifth Assessment Report of the Intergovernmental Panel on Climate Change. Cambridge University Press, Cambridge and New York, pp 899-943

Knutson TR et al (2010) Tropical cyclones and climate change. Nat Geosci 3(3):157-163

Knutson TR et al (2013) Dynamical downscaling projections of twenty-first-century Atlantic hurricane activity: CMIP3 and CMIP5 model-based scenarios. J Clim 26(17):6591-6617

Kopp RE et al (2014) Probabilistic 21st and 22nd century sea-level projections at a global network of tide-gauge sites. Earth's Future 2(8):383-406 
Kopp RE et al (2016) Temperature-driven global sea-level variability in the Common Era. Proc Natl Acad Sci 113(11):1434-1441

Neumann J et al (2011) The economics of adaptation along developed coastlines. Wiley Interdiscip Rev Clim Chang 2(1):89-98

Neumann JE et al. (2014) Joint effects of storm surge and sea-level rise on US Coasts: new economic estimates of impacts, adaptation, and benefits of mitigation policy. Climatic Change

NOAA (2015) Digital Coast Coastal Lidar. Available at: http://coast.noaa.gov/digitalcoast/data/coastallidar [Accessed January 1, 2013]

Parker B et al (2003) A national vertical datum transformation tool. Sea Technology 44:10-16

San Francisco Bay Conservation and Development Commission (2011) Living with a rising bay: vulnerability and adaptation in San Francisco Bay and on its shoreline | Georgetown Climate Center

Strauss BH et al (2012) Tidally adjusted estimates of topographic vulnerability to sea level rise and flooding for the contiguous United States. Environ Res Lett 7(1):14033

Sweet WV, Kopp RE, Weaver CP, Obeyskera J, Horton RM, Thieler ER, Zervas C (2017) Global and regional sea level rise scenarios for the United States. Silver Spring, MD

Tebaldi C, Strauss BH, Zervas CE (2012) Modelling sea level rise impacts on storm surges along US coasts. Environ Res Lett 7(1):14032

US Census Bureau (2012). 2010 TIGER/Line Shapefiles

US Fish and Wildlife Service, "USFWS National Wetlands Inventory," 2010. Available Online: https://www.fws. gov/wetlands/nwi/index.html. Accessed 24 Apr 2017

USGS (2014) Coastal National Elevation Database (CoNED) Project-topobathymetric digital elevation model (TBDEM). Available at: https://lta.cr.usgs.gov/coned_tbdem.

Volkov DL (2003) Annual and interannual variability of sea level in the northern North Atlantic Ocean. J Geophys Res 108(C6):3204 